\title{
An Observation of Cultural and Ideological Impact on Language Behavior
}

\author{
De-Wen SONG ${ }^{1, \text { a }}$ \\ ${ }^{1}$ Hebei University Of Geosciences, Shijiazhuang, Hebei, China \\ asongdewen@sina.com
}

Keywords: Cross-culture communication; Thoughts; Language behavior; Culture interaction

\begin{abstract}
It is generally accepted that culture and thought have influences on language. Culture and language, the two concepts, are closely related. Whenever people want to communicate, they have to take the advantage of language to exchange their ideas, in either written or oral forms. Taking the whole world into consideration, different nations communicate in different ways, so that the way people communicate is the way they live. The author wants to prove that cultural and ideological mode has impact on language behavior by providing convincing discourse corpus. Based on the personal experience, the author concluded that some cultural and ideological influences on language behavior have resulted in such differences and that the cultures are emerging and interacting. When the elements of communication differ or change, the culture make-up differs and changes. As a result, language and culture are inseparable.
\end{abstract}

\section{Introduction}

In terms of intercultural communication there are language barriers which are affected by verbal forms of communication. In this instance there is opportunity for miscommunication between two or more parties. "Other barriers that contribute to miscommunication would be the type of words chosen in conversation do to different cultures there are different meaning in vocabulary chosen, this allows for a message between the sender and receiver to be misconstrued"[1]

It is generally accepted that inter-lingual communication is actually inter-culture communication, and that culture and thought have influences on language. Culture and language, the two concepts, are closely related. Whenever people want to communicate, they have to take the advantage of language to exchange their ideas, in either written or oral forms. As a matter of fact, language is a part of the language, which is the main means the members of the society communicate with each other. "Culture also has a great effect on the perception process. Human perception is usually thought of as a three-step process of selection, organization, and interpretation. Each of these steps is affected by culture.”[2]

Therefore, Language plays a large and significant role in the totality of culture. Far from being simply a technique of communication, it is itself a way of directing the perception of its speakers and it promotes for them habitual modes of analyzing experience into significant categories. Taking the whole world into consideration, different nations communicate in different ways, so that the way people communicate is the way they live. Based on the personal experience, the author concluded that some cultural and ideological influences on language behavior have resulted in such differences and that the cultures are emerging and interacting. When the elements of communication differ or change, the culture make-up differs and changes. As a result, language and culture are inseparable.

Cultural and Ideological ways of thinking is the process of an individual choosing, evaluating and organizing external stimulus, which is the process of changing external stimulus to personal experience. A nation's ways of thinking not only affect individual's social activity, but also affect response of other nations, and the attitude of translated culture towards original culture agreement, appreciation or belittlement, exclusion. 


\section{Language Behavior Differs in Different Culture and Thought}

\subsection{The Impact of Culture on Language}

As we know, language is a tool of the society and social communication. "Language is, as a matter of fact, employed in the society, and the ways in which language is used reflect the culture and that of the people's thought. Therefore, language is definitely influenced by the nation's cultural background.” [3]. Moreover, ideology is closely related with language. Because of the different ideological mode, the way of expression toward a certain subject varies as well. It is, therefore, well known that the impact of Chinese thinking mode has certain passive effect on the thought. English and Chinese have different word arrangement and sentence pattern, so that we have to take such differences, into full consideration, just as the different national ideology is concerned. By a precise comparison of grammar structure and a clear interpretation of the different way of thinking, the communicator will be able to have a explicit knowledge of the grammar.

\subsection{A Featured Chinese Language Behavior}

Davies [4] pointed out that as far as the easterners and the westerners are concerned, Chinese is greatly influenced by her culture background. Chinese people are in a sense of inward and prudent. Compared with Chinese, Americans are frank and straight forward. American people are quite direct. When they feel like something they say "yes" and when they don't, they say "no". We had an American teacher in our university. As colleagues, the teachers working in the same section, we have a lot of co-operations during the course of teaching and researching activities. For the students' sake, several lecturers and professors wrote an English book for the students' achievement tests of different levels. In this book, we need a native speaker to read the Listening Comprehension part as a tape record. We decide on this American teacher to read this part. In our Chinese mood of thinking, we were absolutely positive that he wouldn't refuse as we had been colleagues for over a year, which, in term of Chinese, we were intimate brothers ever since. When asked, to our disappointment, he directly refused us with some excuse. In this case, we Chinese won't do so even if we have difficulties or inconvenience whatsoever.

It is difficult for Chinese people to give a direct refusal. Several years ago, when I taught in another university, a friend of mine asked me to move some furniture to his new apartment. I was then having a bad cold, and I don't know how to refuse but go with him without breakfast. Several hours of labour with heavy furniture, I was totally exhausted and nearly fainted. Back home, I lay in the bed, and wondering why we Chinese are reluctant to say "no"?

A week later, I watched a program named "No Mince Words" on CCTV, and the story was that a sick guy was asked to move to the new house for his friend. He simply died after the heavy work. Immediately the TV Program Director asked an American young man among the audience:

"What would you do if you are asked by a friend to do heavy work when you don't feel well enough"?

"I will directly say 'no'.", the American young man handed the microphone to the program director right away. I was amazed at his being straightforward.

\subsection{A Summery}

Why do people have such difference among different nations? That might have been the reason of the different culture background and different thoughts. Taking the Americans for example, perhaps the key point is that America is a nation of immigrants - it is made up of people from all over the world, all of whom bring their own traditions and habits with them. Thus you needn't worry much about "proper" or "improper" language performance and behaviors. In such a society as America, you have no way to take all the different culture and ideology into account to mind your dos and don'ts. 


\section{Different Attitudes towards Compliments}

\subsection{Chinese and Americans}

The indirect use of language is evident in ways other than the use of "yes" and "no". When Chinese are being praised, they feel embarrassed and awkward at times. An example given by an author of a certain textbook:

"What a beautiful jacket!" one said to the other with admire.

"No, no, not beautiful at all, my father bought me the ugly thing years ago," is the answer.

In the same case, the Americans will act differently. "For example, an American host or hostess, when complimented on his or her cooking, is likely to respond, 'Oh, I'm so glad you like it. I cooked it especially for you.' In contrast, the Chinese host or hostess will 'instead apologize profusely for giving you nothing even slightly edible and for not showing you enough honor by providing proper dishes.' "'[5]

\subsection{A Proper Way to Take Compliments}

What's your reply if you are respected and admired by somebody else? What do you say If you're flustered by praise, it's time to learn how to take a compliment at face value and appreciate the best of it.

\subsubsection{Making a Judgment on the Compliments}

It is truly believed that not all the compliments are sincere enough. Therefore, when you feel uncomfortable on receiving the compliments, you should in a sense decline politely the compliments to stop the compliments being made by the speaker. "The ways of discounting a compliment include: suggesting that it was nothing or that someone else could have done it better, thinking that the person paying you a compliment must be after something from you, being embarrassed and blushing or giving a compliment in return, being sarcastic or insisting that the he or she doesn't mean it"'[6]

\subsubsection{Ways of Acceptance}

"Verbal communication is based on language and use of expression, the tone in which the sender of the message relays the communication can determine how the message is received and in what context”[Wiki, https://en.wikipedia.org/wiki/Intercultural_communication].

You can choose an appropriate response to a compliment depending on whether you'd like to accept the compliment. When accepting the compliment, even if it's not something you agree with, keep the reply simple and stay focused on the fact that you are really appreciate the compliment. The following discourses are might be helpful:

"Thanks a lot!"

"Thank you very much!"

These are the simplest easy ways to convey your acceptance of compliment. Or with more amicable expressions:

"Thanks. That means a lot to me."

"Thanks, I appreciate that."

"Thanks, you're a kind person."

"Thanks - that makes me feel really good."

When accepting a compliment in a way that shows that you're appreciative of the substance of the compliment, this can really help to make the person giving the compliment feel that they've hit the right spot. For examples: "Thanks! I'm so enthusiastic about this, so it's great to know you're keen too."; or rather, "Thanks. I'm really glad you noticed that because it's something I'm proud of too." This is a really good response when somebody has praised your effort.

\section{Cultures and Ideologies Interacting}

\subsection{The Chinese Integrity into the World}

Chinese culture is changing gradually. Years ago, for instance, before the "Opening to the outside world policy" was put into practice, words and expressions such as "Thanks" and "You look very pretty." or "You look young" were considered to be dishonest and hypocritical. Nevertheless, 
with the development of the society, these expressions are acceptable to Chinese people. As a matter of fact, giving or receiving compliments is an acceptable part of making daily communication. Offering compliments is also a good way for Chinese to make a light and an acceptable conversation.

"From a long history, Chinese people lived a comparatively isolated life, and they considered foreign languages and cultures are alien, and detached, with were misfits"[7]. With the involvement and an amalgamation of China into the world culture, Chinese people are greatly integrated into this global culture. Nowadays, for instance, people know quite well if someone claims that: "Wait a moment; I want to wash my hands". Nevertheless, about one or two decades ago in China, fewer people knew this western culture. A good case by Professor Song Dewen [8] can illustrate this point: A group of leaders and professors in our College Teaching Department were attending a meeting in the department laboratory. With the time went on, one of the leaders said (in Chinese) to the director of the Department: "Wait, I'd have to wash my hands." However, the director warmly suggested: "You can wash your hands in this Laboratory; here we have so many washing basins in the lab." The fact is that the senior old director was not aware of that western culture with euphemism to avoid a taboo. However, this leader who knew this culture is a professor teaching English.

\subsection{The World's Acceptance of the Chinese}

Nisbett [9] points that the Geography of Thought: How Asians and Westerners Think differently....and Why. New York, NY: Free Press.] and others contend that Eastern and Western cultures literally perceive different worlds. Modern Eastern cultures are inclined to see a world of substances - continuous masses of matter. Modern Westerners see a world of objects-discrete and unconnected things. There is substantial evidence that Easterners have a holistic view, focusing on continuities in substances and relationships in the environment, while Westerners have an analytic view, focusing on objects and their attributes.

With a process of global economy and information, China has successfully integrated into the world cultures and languages. And vice versa, the world cultures also accepted and hugged the Chinese culture. To our delight, we may find in recent years, some international enterprises take the Chinese culture and traditions into their enterprising strategies. Otherwise, they are not able to carry on a smooth dealing and achieve a successful performance.

Nowadays, as we approach into the new century, various factors drive people as never before across national boundaries so frequently, making intercultural contact a major concern for the new century.

\section{Conclusion}

Through a detailed investigation the author proved that cultural and ideological mode has impact on language behavior by providing convincing discourse corpus. Based on the personal experience, the author concluded that some cultural and ideological influences on language behavior have resulted in such differences and that the cultures are emerging and interacting. When the elements of communication differ or change, the culture make-up differs and changes. With the rapid development of the world economy, and the growth of population, it becomes more and more difficult for people to remain detached and isolated themselves from the outside world.

Language and culture are closely related. It is academically accepted that language is the carrier of culture. And culture has a close relation with business and trade. More than ten years ago, the economy of the world was polarized into two separate and competing powers: the East and the West. However, changes and advancements in economic relationships, political systems, and technological options began to break down the international regional cultural barriers. With the process of the globalization of the world economy, and as far as economic management is concerned, business transformed from individual-country capitalism to global capitalism. Thus, the study of cross-cultural communication was originally found within businesses and government, both seeking to expand globally. Businesses began to offer language training to their employees and 
programs were developed to train employees to understand how to act when abroad, as Wikipedia [10] information reveals.

\section{References}

[1] R. Scollon, and S.K.Scollon, Intercultural communication: a discourse approach MA: Blackwell Publishers, 2001.

[2] H.Tajfel, “Cognitive aspects of prejudice”. Journal of Social Issues, 1996, 25, 79-97.

[3] W. Dai, "Problems on talents development strategy oriented training in twenty-first Century", Foreign Languages World (4) 2001, 14-22

[4] P. Davies and E. Pearse, Success in English Teaching. 1st ed. oxford, Eng: Oxford University Press. 2002, pp. 275

[5] Samovar, Porter and Stefani, Communication between Cultures, Wadsworth Publishing Company, USA, 1998

[6] Wiki http://www.wikihow.com/Take-Compliments 2016.

[7] Y. Deng, A relation between Chinese text model and English writing. Journal of Xi'an Foreign Languages Institute, (4), 1999, 22-26.

[8] D. Song, A Stylistic Study of English Contract and Translation. 1st ed. Beijing, China: Beijing University Press. 2006, pp. 68

[9] N. Richard. The Geography of Thought: How Asians and Westerners Think Differently...and Why. New York, NY: Free Press. 2003

[10] Wiki http://www.wiki.com/ 2016. 